\title{
Late Onset of Prescription Drug Abuse or Dependence Among Older Adults: Implications for Treatment
}

\author{
Kathy Lay \\ LucyJ. King
}

\begin{abstract}
Prescription drugabuseand dependenceisan increasing concern for older adults. This article describes issues specific to older adults with late onset abuse or dependenceon prescription sedativesand/or opiates. Theolder adult with lateonset should not be viewed as having the same issues as individuals who havea life pattern of drug and alcohol abuse/dependence. A chart review of older adults in a treatment program contrasts lateonset prescription dependence dients $(n=12)$ and early onset addiction clients $(n=104)$ and outlines differences and si milarities betwen the two samples. Social workers need to understand the specific and changing needs of older adults as they relate to assessment and treatment of drug abuse and dependence
\end{abstract}

Keywords: Addiction and theaged, sedative/opiateabuse and/or dependence

\section{ELDERLY AS A GROMING POPULATION AT RISK OF DRUG ABUSE}

The older adult population, those 65 and older, will grow exponentially at a rate greater than in previous years. At the turn of the century, older adults were a small portion of the total population; however, projections indicate that, by the year 2030, older adults will make up $21 \%$ of the total population (Berkman, 2006). The growing aging population represents the success of industrialized countries and, at the same time, presents challenges to health care providers (Kinsella \& Velkoff, 2001). Like no previous generation, aging adults have experienced increased opportunity for illicit drug abuse and increased availability of prescription drugs developed by new technologies to address a spectrum of emotional and physical illnesses. The advent of both brings challenges for care providers of pain management, addictions treatment, and case management of the older adult.

Older adults, like younger individuals, abuse the same types of substances: alcohol, prescription drugs, and illicit drugs (Shibusawa, 2006; Simoni-Wastila \& Yang, 2006). For many years, alcohol continues to be the leading drug abused by older adults (SAMHSA, 2003). However, the last decade brought projections regarding

Kathy Lay, Ph.D. is an assistant professor, Indiana University School of Social Work, Indiana University School of Social Work, Indianapolis, IN 46202-5156. LucyJ. King, M.D. isclinical professor emeritus in psychiatry at the Indiana University School of Medicine, Indianapolis, IN 46202.

Copyright 2007 Advances in Social Work Vol. 8 No. 2 (Fall 2007) 264-274.

Indiana University School of Social Work. 
an increasing concern for prescription drug abuse and dependence in older adults (Anderson \& Kerluke, 1996). Misuse and abuse of prescription medications has long been widespread among older adults (Barnea \& Teichman, 1994). Older adults take medications more frequently; they are three times more likely than younger adults to use prescription drugs, and use of over-the-counter medications is also a concern (Patterson \& Jeste, 1999). "Thirty percent of all prescription drugs are prescribed for elderly persons and many of these medications are psychotropics" (Bogunovic \& Greenfield, 2004, p. 233). It is estimated that the aged spend "between $\$ 2,000$ and $\$ 3,000$ per person per year on prescription drugs" (Moxey, O'Connor, Novielli, Teutsch, \& Nash, 2003, p. 140).

Older adults are more likely to use prescription drugs due to a variety of chronic illnesses, thus their annual costs of drugs are much higher than that of others. It is estimated that those 60 and older are taking, on average, five different medications (Oslin, 2000). They are also a group that is least likely to have supplemental insurance to cover the cost of drugs, although the still controversial Medicare Prescription Benefit may alter the situation. The annual out-of-pocket cost of medications can be as high as $\$ 9,000$ (Angell, 2004). The high cost of medications is another aspect in the non-compliance of prescribed medications, which can also be a factor in abuse/ dependence. Facing financial constraints can bring about drug swapping, reliance on over-the-counter drugs that are ineffective, or the use of stored medications that are either out-of-date or inappropriate for the illness.

Individuals abusing alcohol or taking multiple drugs are at risk for poor compliance (Braithwaite et al., 2005; Anderson \& Kerluke, 1996). Patterns of misuse and abuse associated with medications among the aging population include misunderstanding how a medication is to be dosed or used, use of multiple medications with potential for harmful interaction, and use when it is contraindicated (Barnea \& Teichman, 1994). All of these patterns can contribute to abuse or dependence.

The prescription drugs that are most commonly prescribed and have the potential for abuse are sedatives and opiates (Meadows, 2001), two classes of prescription medications that can lead to addiction (substance dependence). Sedatives include barbiturates and benzodiazepines. The prevalence of benzodiazepine use among older adults is widespread, despite its well-known adverse effects (Cook, Marshall, Masci, \& Coyne, 2007). Opiates are morphine-like painkillers. The risk of dependence on these drugs increases with age and with chronic medical conditions requiring multiple medications (Bogunovic \& Greenfield, 2004).

As the population of older adults increases over the next decade, so will the demands for mental health and addictions treatment specific to the aging population (Satre, Knight, Dickson-Fuhrmann, \& Jarvik, 2004). Likewise, the increase of prescription medications for illnesses associated with aging processes will bring potential abuses.

The past two decades have seen research differentiating individuals who begin addicting substance abuse when young or middle-aged from those who begin abuse of addicting substances at age 50 or older. These studies have dealt primarily with alcohol abuse (Atkinson, Turner, Kofoed, \& Tolson, 1985; Liberto, Oslin, \& Ruskin, 1992; Sattar, Petty, \& Burke, 2003). The focus of this article will be those 
older adults whose addiction began at age 50 or older and were diagnosed as having abuse or dependence on prescription sedatives, opiates, or both.

\section{SPECIAL ISSUES FOR ELDER SUBSTANCE ABUSERS}

\section{Addiction Treatment: Identification and Diagnosis}

Identification with an addiction culture may be a daunting task for older adults. The culture of addictions treatment asks individuals to "negotiate both a new social as well as personal identity... [helping] move clients from addiction into recovery" (Matto, 2004). Some may choose self-identification as an "addict" and may experience it as empowering. This is a common practice in addiction treatment. Historically, older adults have viewed addiction as a moral failure, a source of shame, and stigma (Satre, Knight, Dickson-Fuhrmann, \& Javrik, 2004). Therefore, the initial task is to provide a complete biopsychosocial assessment that establishes a need for treatment that both the client and family can collaboratively understand. The older adult with late onset should not be viewed as having the same issues as individuals who have a life pattern of drug and alcohol abuse/ dependence.

There is a great deal of misunderstanding among the public and health care professionals alike about what constitutes addiction. Accurate understanding involves consideration of both diagnostic criteria and pharmacology (Erickson, 2007). Substance dependence, alcoholism, or drug addiction is officially diagnosed using the DSM-IV-TR (American Psychiatric Association, 2000) as having a pattern of three or more of seven specific symptoms within a 12-month period: 1) tolerance, needing more and more to achieve the same effect of the drug; 2 ) withdrawal, a characteristic set of symptoms for each class of addicting drugs on stopping heavy use; 3) taking more of the substance for a longer time than intended; 4) "persistent desire or unsuccessful efforts to cut down" (p. 197); 5) spending a great deal of time obtaining, using, and recovering from effects of use; 6) giving up important "social, occupational, or recreational activities" (p. 197) because of use; 7) continuing use despite having frequent physical or psychological problems related to use (American Psychiatric Association, 2000).

Loss of control of use (symptoms 3 and 4) and psychosocial factors (symptoms 5,6 , and 7 ) indicate that the use of the substance is taking over the individual's life. It would be theoretically possible for an individual to meet criteria for three symptoms with any three of these five symptoms (i.e., without tolerance and withdrawal symptoms). Conversely, tolerance and withdrawal, alone, do not meet criteria for three symptoms. Older adults having abuse or dependence on sedatives or opiates may fall into this grouping.

Withdrawal symptoms from sedatives are medically dangerous as well as distressing. Opiate withdrawal is extremely unpleasant, including having generalized pain. Tolerance and withdrawal, alone, are simply pharmacologic properties of long-term use of moderate doses of sedatives and opiates. What appears to be "drug-seeking behavior" might simply be the result of an individual's attempts to stop medication and finding it produces painful and distressing symptoms. This, in turn, can result from long-term prescription use without careful follow-up and 
failure to explain the nature of the medication to theindividual. Pohl (2004) noted that, what is frequently viewed as "drug-seeking" behavior, is often a reflection of poor pain management, and typical addiction is characterized by deviant behaviors. These behaviors may not be typical of this late onset population.

\section{Chronic Pain and Management}

Chronic pain is another concern for the older adult and, particularly, proper management of chronic pain. Benzodiazepines are inadequate in treating pain despite the evidence that between $40 \%$ and $60 \%$ of those struggling with chronic pain are prescribed these medications (Kranzler \& Ciranulo, 2005). Analgesics, opiates, and non-opiates are the most commonly prescribed pain medications, and older adults are most likely to have prolonged use. Studies suggest that even low-dosage, long-term use of opiates can produce tolerance or dependence (Edwards \& Salib, 2001). Individuals with chronic pain, regardless of addictive disorders, experience pain in the same way as others and must be treated aggressively with appropriate pain management (Pohl, 2004). A tension exists between addiction treatment and pain management.

Addiction treatment providers tend to focus on abstinence from all addicting substances, including opiates, while pain treatment professionals focus on relief of pain using aggressive medication prescription with less concern about addiction. Both want to alleviate problems for the client and are challenged by the issues of pain and addiction. Assessment of pain, especially in individuals with a history of or current diagnosis of substance dependence, is complex.

"Pain is experienced and perceived by an individual with an addictive disorder in just the same way it is experienced and perceived by healthy non-addicted patients" (Pohl, 2004, p. 121). In any individual with chronic pain, it is important that careful medical, psychiatric, and substance dependence evaluation be administered and all illnesses betreated. Multiple modalities for the relief of pain, including non-pharmacologic means, should be employed in collaborating with an individual in order to find out what works or does not work. Non-pharmacologic therapies include: psychotherapy, physical therapy, occupational therapy, hypnosis, acupuncture, non-addicting medications, meditation, and others (Gunderson \& Stimmel, 2004). Ongoing assessment, frequent contact with the client, and modification of treatment plans as indicated, prevents the kinds of problems faced by this special population of aging adult.

\section{Chronic Illnesses}

Many older adults struggle with chronic illnesses and pain associated with aging. Chronic illness and pain may be exacerbated by abuse and dependence (Finlayson \& Hofmann, 2002). Addiction treatment providers must engage these clients on behalf of their health benefits and costs. The treatment process must work to build an understanding that recovery management can provide the client with valuable tools that can assist in their autonomy and quality of life without their having to identify as an "addict."

Many see older adults as a population with sleep problems, chronic pain, and therefore in need of sedatives and analgesics; however, use and certainly abuse of 
these drugs adds to morbidity and dysfunction of older adults (Finlayson \& Hofmann, 2002). Misuse, abuse, and dependence on sedatives and opiates used in combinations with alcohol create the "potential for serious consequences, such as falls, automobile accidents, or even death" (Pringle, Ahern, Heller, Gold, \& Brown, 2005, p. 1930). Alcohol use, even in small amounts, further compromises the individual's health, that is, using multiple medications (Pringle et al., 2005).

Older adults are likely to be under medical care for chronic illnesses, such as heart disease, diabetes mellitus, and arthritis (Finlayson, 1997). Adults in addiction treatment often have co-morbidity with diseases associated with addictions, such as COPD, liver disease, and peptic ulcers. In that this group of older adults with late onset does not have a long history of substance dependence, it is quite possible that they may not be likely to struggle with chronic illnesses associated with addiction as do populations that have a long history of abuse or dependence on alcohol and illicit drugs. Due to the late onset, there is no prolonged use that is associated with liver disease, peptic ulcers, and chronic obstructive pulmonary disease.

\section{Co-occurring Disorders in Older Adults}

Studies have established that mood and anxiety disorders develop independent of addiction and they are the most common psychiatric disorders (Grant et al., 2004). Stromwall and Larson (2004) found that women with co-occurring substance abuse are seven times more likely than men to be diagnosed with posttraumatic stress disorder and are significantly more likely to have anxiety and mood disorders. This points to a strong need for a thorough psychosocial assessment of older women, as well as integrated treatment, addiction, and mental illness treatment, simultaneously.

Women, and in particular, older women, are less likely to be screened and diagnosed for alcohol and drug abuse/ dependence, and they are more likely to have a psychiatric diagnosis and also increased use of prescription drugs (Satre, Mertens, \& Weisner, 2004). The use of sedatives is more prevalent among women (Bogunovic \& Greenfield, 2004). Women may be prescribed sedatives appropriately for anxiety disorders, but inappropriately for other issues, such as grief management or the catch-all phase, "nerve problems." The latter are indicative of gender-biased misdiagnosis at best, and practices that do not meet the standard of care, at worst. Older women are candidates for addiction treatment, but their needs may differ significantly from clients with a history of addiction, inclusive of alcohol and illicit drug dependence. These individuals must be assessed carefully for co-occurring psychiatric disorders and evaluated properly for the continuation of psychotropic medication and psycho-social interventions, such as cognitive-behavioral treatment.

\section{Family Assessment and Treatment}

It has long been established that substance dependence affects the family, that these disorders run in families, and that families are distressed by the consequences of drug abuse and dependence (Steinglass \& Kutch, 2004). Family history is often seen as a predictor for abuse or dependence on drugs and alcohol. This special population with late onset may not present with this history, and this 
should not be a variable utilized to formulate a diagnosis or prognosis. However, Steinglass and Kutch point out that "inclusion of the family as a central partner in the therapy process significantly improves treatment outcomes" (p. 405). The family and client working together will serve to enhance recovery. Complex clinical issues, such as substance abuse and dependence, combined with chronic illness, chronic pain, and psychiatric disorders, require collaboration in decisions related to their health care. "Patients and their families are increasingly seeking more active participation in health care decision making as they are faced with more complex clinical choices" (Berkman, Gardner, Zodikoff, \& Harootyan, 2005, p. 333).

\section{Ageism}

Kelchner (1999) points out how costly ageism is to individuals and society. Ageism and sexism are of particular concern for this group of older adults who abuse or are dependent on drugs. Both sexism and ageism prevent the older clients with prescription addiction from being seen in the context of their particular struggles with addiction and co-occurring psychiatric or physical disorders. Belonging to two groups (elderly and female), which are sometimes stereotyped and patronized, can be costly in that they go for a prolonged period of time without proper treatment. Older adults are often stereotypically viewed as a declining group that no longer contribute economically (Kane, 2004), and a younger population may be more likely to get the attention of addiction treatment providers in that resources are limited. Older adults in treatment may only represent 3\% (SAMHSA, 2004) of the total population in treatment for substance dependence, and this may further serve as misguided statistical evidence to support less attention to the older adult in need of treatment for substance abuse and dependence.

Little attention has been paid to this specific population, and this compromises an individual's understanding of the necessity for treatment. These key issues (assessment, chronic pain management, chronic illnesses, co-occurring disorders, family issues, and ageism) are particularly important in assessing older adults who have potential prescription abuse concerns. The initial identification of prescription dependence in older adults can be masked by the context of illness, pain, changes in the family, and stereotypic views of aging clients. Social workers must fully comprehend the effects of these drugs, educate clients and their families, and advocate for medical detoxification and evaluation.

\section{METHODOLOGY}

This study was obtained from the medical records of patients age 55 and older who were admitted as inpatients for the first time to a Midwestern non-profit addiction treatment facility in either 1992 or 2002. A larger study focusing on changing drug use patterns is published elsewhere (Lay, King, \& Rangel, in press). This study analyzed individuals who were diagnosed as either abusing or were dependent on prescription sedatives and/ or opiates.

The aims of the current study were to (a) provide a descriptive summary of the prescription abuse subpopulation, (b) contrast older prescription abusers ( $n=12$ ) and older abusers of alcohol and/or illicit drugs $(n=104)$ on key factors, and (c) 
determine if there were differences in the characteristics of older prescription abusers. The Internal Review Board of a university approved the study.

Charts from a private non-profit addiction treatment facility in a midsized city were reviewed retrospectively from the year 1992 and 2002 for a total of 2,313 individuals admitted to all levels of treatment. Individuals age 55 and older having a single admission to inpatient treatment were identified $(N=116)$, representing $5 \%$ of the total admission from the two cohorts. Data were recorded on standardized forms and entered into a database for analyses (Lay, King, \& Rangel, in press). This article focuses of those older adults who began using addicting substances at age 50 or older $(n=12)$ and, more specifically, those whose drug abuseand dependence was restricted to sedatives and opiates.

\section{RESULTS}

Of the 2,313 individuals admitted to treatment from the two cohorts, 1992 and 2002, 116 met the study criteria, having a single admission to inpatient treatment at age 55 or older upon admission. This represents $5 \%$ of the single admissions to all treatment programs at the facility. The mean age of first use for all subjects ( $\mathrm{N}=116)$ was 23 years of age. Illicit drug users (specifically, marijuana, cocaine, and heroin) were found only in the 2002 cohort, with a mean age of first use of 15 years of age. Including both cohorts, $27 \%$ reported previous psychiatric treatment. At the time of admission $34 \%$ of the 2002 cohort were diagnosed with a co-occurring psychiatric disorder as compared to only $10 \%$ of the 1992 cohort. The 1992 cohort had more diagnoses of illnesses associated with addictions (COPD, liver disease, and peptic ulcer) than the 2002 group. For all individuals in both groups, alcohol was the first and primary drug of abuse or dependence, with the exception of 12 individuals who began using at age 50 or older (Lay, King, \& Rangel, in press).

Twelve (12) individuals began use of addictive substances at age 50 or older. This represents $10 \%$ of the total sample $(\mathrm{N}=116)$. Eight $(8)$ of the 12 individuals were from the 2002 cohort and four were from the 1992 cohort. The mean age of onset for this group was age 61, and the mean age at the time of admission was 69. This sets them apart from the larger group, primarily diagnosed with abuse or dependence on alcohol, which had a mean age of onset of 23 . Four of the 12 individuals, two males and two females, abused or were dependent on alcohol. The remaining eight people abused or were dependent on prescription sedatives and/or opiates. Of the eight individuals, seven were women. This represents $20 \%$ of the females from the total sample. Only one individual had a positive family history for addiction. Only women reported chronic pain. Four women had a diagnosis of anxiety or mood disorders. This group had a variety of medical illnesses typically associated with the aged: hypertension, diabetes, and cardiac disease. Almost half of the older adults with late onset in this study were diagnosed with a mood or anxiety disorder at admission or during treatment for addiction. They are all female.

\section{TREATMENT IMPLICATIONS}

This special population of older adults diagnosed with abuse of or dependence on prescription sedatives and/ or opiates represents a small group of individuals who enter treatment for addiction and are in need of special ized treatment. These were 
individuals who either self-referred or were identified by health care providers as being in need of detoxification and treatment; however, there may be others treated in other inpatient settings or with poor attention to the inappropriate use of medication. Late onset, age 50 or older, sets them apart from those individuals typically entering addictions treatment who have a history of chronic abuse or dependence of multiple drugs inclusive of alcohol and who often identify themselves as "addicts." This group of older adults entering treatment for addiction, averaging 69 years of age, has no documented history of abuse/dependence in their younger years.

\section{CONCLUSIONS}

The older adults with late onset of abuse or dependence on prescription sedatives and or opiates are predominately women, who use alcohol occasionally or not at all. They tended to have chronic pain and did not report positive family histories of substance abuse or dependence. It can beconjectured that these individuals are not only atypical substance dependent individuals, but they are also individuals with inappropriate pain management.

Generalizability cannot be reached from this small sample; however, we are provided with valuable information about treatment implications and further research for this group of older adults. Systematic, prospective follow-up of larger numbers of individuals will be necessary to determine treatment outcomes of this group and to design specific treatment strategies.

Specific knowledge related to abuse of or dependence on opiates and benzodiazepines is paramount. These drugs can cause confusion and unsteadiness in this population, predisposing them to falls (Kurzthaler et al., 2005), another matter of concern, which is directly related to quality of life. Although widely used with the elderly, these drugs account for impairment in functionality, escalation of abuse, and often result in morbidity and, in some instances, mortality (Lantz, 2005). In addition, benzodiazepine withdrawal is the most dangerous of all withdrawals medically.

Predictions for the future are that there will be increasing numbers of women among the substance-dependent population (Grant, Dawson, Stinson, Chou, Dufour, \& Pickering, 2004) and that they will present specific needs in addiction treatment (Blow, 2000). Most likely, abuse or dependence of opiates and sedatives will be a primary treatment concern for this population. These are not the "typical" individuals admitted to addiction treatment. This group requires a different approach to treatment than the traditional addiction treatment that tends to be group oriented and, at times, confrontational regarding denial. The use of nonaddicting pain treatment modalities, such as physical therapy, occupational therapy, acupuncture, non-addicting medication, and support groups focusing on management of pain and disability are indicated in the context of cognitive behavioral therapy.

Older adults entering treatment for substance abuse and dependence are not a homogeneous group (Lay, King, \& Rangel, in press). Social workers and health care providers of the older adult must understand assessment of substance abuse and 
dependence, management of chronic pain, chronic illness, co-occurring psychiatric disorders, family assessment, and ageism-all important concerns related to the older adult entering addiction treatment. Substance abuse among the aged is "overlooked and underreported....presentation may be atypical and hence easily missed by the medical practitioner" (McGrath, Crome, \& Crome, 2005, p. 228). Social work practitioners working in settings with older adults must complete a biopsychosocial evaluation that includes a listing of all medications, historical, and current use, with the understanding that the prescribed dosage may be problematic or used incorrectly. Pain management is critical to understanding treatment of the older adult. Social workers must be prepared to provide clients with psycho-education and appropriate referral to pain management as well as addiction treatment when indicated.

Social workers are trained to view people from an ecological lens, and this lens, including a multidisciplinary approach, is a necessity in order to address the complexity of issues the older adult brings to treatment settings (Berkman, Gardner, Zodikoff, \& Harootyan, 2005). Social work curricula and continuing education must include content specific to gerontology and produce research that will inform practice specific to the complex addiction treatment needs of the older adult.

\section{References}

American Psychiatric Association. (2000). Diagnostic and statistical manual of mental disorders IV-TR. Washington, D.C: Author.

Anderson, G., \& Kerluke, K. (1996). Distribution of prescription drug exposures in the elderly: Description and implications. Journal of Clinical Epidemiology 49(8), 929-935.

Angell, M. (2004). Thetruth about the drug companies. New York: Random House.

Atkinson, R., Turner, J., Kofoed, L., \&Tolson, R. (1985). Early versus late onset alcoholism in older persons: Preliminary findings. Alcoholism: Clinical and Experimental Research 9(6), 513-515.

Barnea, Z., \&Teichman, M. (1994). Substance misuse and abuse among the elderly: Implications for social work intervention. Journal of Gerontological Social Work, 21(3/4), 133-148.

Berkman, B. (Ed.). (2006). Handbook of social work in health and aging. New York: Oxford University Press.

Berkman, B., Gardner, D., Zodikoff, B., \& Harootyan, L. (2005). Social work in health care with older adults: Future challenges. Families and Society 86(3), 329-337.

Blow, F. (2000) Treatment of older women with alcohol problems: Meeting the challenge for a special population. Alcoholism: Clinical and Experimental Research 24(8), 1257-1266.

Bogunovic, O., \& Greenfield, S. (2004). Use of benzodiazepines among elderly individuals. Psychiatric Services, 55(3), 233-235.

Braithwaite, R.S., McGinnis, K.A., Conigliaro, J., Maisto, S.A., Crystal, S., Day, N., Cook, R.L., Gordon, A., Bridges, M.W., Seiler, J.F., \& Justice, A.C. (2005). A temporal and dose-response association between alcohol consumption and medication adherence among veterans in care. Alcoholism: Clinical and Experimental Research, 29(7), 1190-1197.

Cook, J.M., Marshall, R., Masci, C., \& Coyne, J.C. (2007). Physicians' perspectives on prescribing benzodiazepines for older adults: A qualitative study. Journal of General Internal Medicine22(3), 303-307.

Edwards, I., \& Salib, E. (2001). Analgesics in the elderly. Aging and Mental Health 6(1), 88-92.

Erickson, C.K. (2007). Thescience of addiction: From neurobiology to treatment. New York: WW Norton. 
Finlayson, R. (1997). Misuse of prescription drugs. In A.M. Gurnack (Ed.). Older adults' misuse of alcohol, medicines, and other drugs. New York: Springer Publishing.

Finlayson, R., \& Hofmann, V. (2002). Prescription drug misuse: Treatment strategies. In A.M. Gurnack, R. Atkinson, \& N.J. Osgood (Eds.). Treating alcohol and drug abuse in the elderly (pp. 155-174). New York: Springer Publishing.

Grant, B., Stinson, S., Dawson, D., Chou, P., Dufour, M., Compton, W., Pickering, R., \& Kaplan, K. (2004). Prevalence and co-occurrence of substance use disorders and independent mood and anxiety disorders: Results from the national epidemiologic survey on alcohol and related conditions. Archives of General Psychiatry 61, 807-816.

Grant, B., Dawson, D., Stinson, F., Chou, S., Dufour, M., \& Pickering, R. (2004). The 12-month prevalence and trends in DSM-IV alcohol abuse and dependence: United States, 1991-1992 and 2001-2002. Drug and Alcohol Dependence, 74, 223-234.

Gunderson, E.W., \& Stimmel, B. (2004). Treatment of pain in drug-addicted persons. In M. Galanter \& H.D. Kleber (Eds.). Textbook of substance abuse treatment, ( $3^{\text {rd }}$ ed.,pp. 563-573). Washington, D.C.: American Psychiatric Publishing, Inc.

Kane, M.N. (2004). Predictors for future work with elders. Journal of Gerontological Social Work, 42(3/4), 19-38.

Kelchner, E.S. (1999). Ageism's impact and effect on society: Not just a concern for the old. Journal of Gerontological Social Work 32(4), 85-100.

Kinsella, K., \&Velkoff, V.A. (2001). An aging world: 2001, International population reports(U.S. Department of Health and Human Services, NIH, National Institute on Aging). U.S. Census Bureau.

Kranzler, H., \& Ciranulo, D. (2005). Clinical manual of addiction psychopharmacology. Washington, D.C.: American Psychiatric Publishing, Inc.

Kurzthaler, I., Wambacher, M., Golser, K., Sperner, G., Sperner-Unterweger, B., Haudekker, A., Pavlic, M., Kemmler, G., \& Fleischhacker, W.W. (2005). Alcohol and benzodiazepines in falls: An epidemiological view. Drug and Alcohol Dependence, 79(2), 225-230.

Lantz, M. (2005). Prescription drug and alcohol abuse in an older woman. Clinical Geriatrics, 13(1), 39-43.

Lay, K., King, L.J., \& Rangel, J. (in press). Journal of Social Work Practice in theAddictions.

Liberto, J., Oslin, D., \& Ruskin, P. (1992). Alcoholism in older persons: A review of the literature. Hospital Community Psychiatry, 43, 975-984.

Matto, H. (2004). Applying an ecological framework to understanding drug addiction and recovery. Journal of Social Work Practice with Addictions, 4(3), 5-22.

McGrath, A., Crome, P., \& Crome, I. (2005). Substance misuse in the older population. Journal of Postgraduate Medicine, 81, 228-231.

Meadows, M. (2001). Prescription drug use and abuse. Food and Drug Administration Consumer (Sept./Oct.), 19-24.

Moxey, E., O'Connor, J., Novielli, K., Teutsch, S., \& Nash, D. (2003). Prescription drug use in the elderly: A descriptive analysis. Health CareFinancing Review, 24(4), 127-141.

Oslin, D.W. (2000). Prescription and over-the-counter drug misuse among the elderly. GeriatricTimes, 1(1), Retrieved August 8, 2006, from: http:// www.geriatrictimes.com/g000629.html.

Patterson, T.L., \&Jeste, D.V. (1999). The potential impact of the baby-boom generation on substance abuse among elderly persons. Psychiatric Services, 50(9), 1184-1188.

Pohl, M. (2004). Pain in special populations: Syllabus. In A. Heit \& S. Savage (Eds.). Pain and Addiction: Common ThreadsV, (pp. 121-126). Washington, D.C.: American Society of Addiction Medicine.

Pringle, K.E., Ahern, F.M., Heller, D.A., Gold, C.H., \& Brown, T.V. (2005). Potential for alcohol and prescription drug interactions in older people. Journal of theAmerican Geriatrics Society, 53(11), 1930- 1936.

SAMSHSA. (2004, May). Older Adults in substance abuse treatment: 2001. (The DASIS Report). Washington, D.C.: Office of Applied Studies, SAMHSA. 
SAMHSA. (2003). Survey: Nearly half in treatment for both drugs and alcohol abuse (Volume XI, Number 4). Retrieved January 31, 2006, from SAMHSA News, via: http://alt.samhsa.gov/samhsa_news/VolumeXI_4/ article5.htm.

Satre, D., Knight, B., Dickson-Fuhrmann, E., \& Javrik, L. (2004). Substance abuse treatment initiation among older adults in the GET SMART program: Effects of depression and cognitive status. Aging and Mental Health, 8(4), 346-354.

Satre, D., Mertens, J., \&Weisner, C. (2004). Gender differences in treatment outcomes for alcohol dependence among older adults. Journal of Studies on Alcohol, 65(5), 638-642.

Sattar S., Petty F., \& Burke W. (2003). Diagnosis and treatment of alcohol dependence in older alcoholics. Clinical Geriatric Medicine, 19(4), 743-761.

Shibusawa, T. (2006). Older adults with substance/alcohol abuse problems. In B. Berkman (Ed.), Handbook of social work in health and aging (pp. 141-147). New York: Oxford University Press.

Simoni-Wastila, L. \& Yang, H.K. (2006). Psychoactive drug abuse in older adults. The American Journal of Geriatric Pharmacotherapy, 4(4), 380-394.

Steinglass, P., \& Kutch, S. (2004). Family therapy: Alcohol. In M. Galanter \& H.D. Kleber (Eds.), Textbook of substanceabusetreatment ( $3^{\text {rd }}$ ed.) (pp. 405-415). Washington, D.C.: American Psychiatric Publishing.

Stromwall, L., \& Larson, N. (2004). Women's experience of co-occurring substance abuse and mental health conditions. Journal of Social Work Practicein Addictions, 4(1), 81-96.

\section{Author's Note:}

Address correspondence to: Kathy Lay, Ph.D., Indiana University School of Social Work, 902 West New York Street, Indianapolis, IN 46202. e-mail: kalay@iupui.edu.

This research was supported in part by a grant from the Central Indiana Coalition on Aging (CICOA). 